\title{
On the Growing Role of Observation, Formalization and Experimental Method in Musicology
}

\author{
HENKJAN HONING \\ University of Amsterdam
}

\begin{abstract}
In the last two decades an important shift has occurred in music research, that is, from music as an art (or art object) to music as a process in which the performer, the listener, and music as sound play a central role. This transformation is most notable in the field of systematic musicology, which developed from "a mere extension of musicology" into a "complete reorientation of the discipline to fundamental questions which are non-historical in nature, [encompassing] research into the nature and properties of music as an acoustical, psychological and cognitive phenomenon" (Duckles \& Pasler, 2001). Three recent strands of music research will be briefly discussed, namely empirical, computational, and cognitive musicology. They will be interpreted in the context of the "cognitive revolution" in the humanities and the sciences.
\end{abstract}

Submitted 2005 April 2; accepted 2005 April 27.

KEYWORDS: cognition, computational, empirical, epistemology, method, musicology

\section{INTRODUCTION}

THE term "musicology" has been defined in many different ways. In 1955, the American Musicological Society described it as "a field of knowledge having as its object the investigation of the art of music as a physical, psychological, aesthetic, and cultural phenomenon." The attributes used here give the definition of musicology considerable breadth, although "music as an 'art' remains the focus of attention" (Duckles \& Pasler, 2001). However, in the last two decades an important shift has occurred, that is, from music as an art (or art object) to music as a process in which the performer, the listener, and music as sound play a central role. This transformation is most notable in the field of systematic musicology (a term introduced by Adler, 1885), which developed from "a mere extension of musicology" [1] into a "complete reorientation of the discipline to fundamental questions which are non-historical in nature, [encompassing] research into the nature and properties of music as an acoustical, psychological and cognitive phenomenon" (Duckles \& Pasler, 2001).

This reorientation did not take place exclusively in systematic musicology. For example, much of the pioneering work in the field of ethnomusicology stressed the importance of systematic methods and the need to study music in its wider social, anthropological, and cultural context (e.g., Kunst, 1950; Seeger, 1991). But systematic methods also gained more ground in, for example, the semiotic approach to music (e.g., Nattiez, 1987). In addition, there are several ongoing developments in musicology that promote interdisciplinary research within the humanities (e.g., Kerman, 1985; McClary, 1991). [2]

In this text three recent strands of musicological research will be discussed, namely empirical, computational, and cognitive musicology. They will be interpreted in the context of the "cognitive revolution" in the humanities and the sciences.

\section{The Role of Observation: Empirical Musicology}

Empirical musicology grew out of a desire to ground theories on empirical observation and to construct theories on the basis of the analysis and interpretation of such observations (cf. Rink, 1995; Clarke \& Cook, 2004). The arrival of new technologies, most notably that of MIDI and of the personal 
computer, were instrumental to the considerable increase in the number of empirically oriented investigations into music (Clarke, 1999; Gabrielsson, 1999). Huron (1999b) refers to this reorientation as "new empiricism" and considers it, along with "new musicology," the most influential movement in recent music scholarship. Huron stresses that this transformation arose within music scholarship, and he promotes the adaptation of scientific methods, such as "the pursuit of evidence and rigor" — in spite of the criticism of scientific methods in the postmodern literature (cf. Natoli, 1997). In fact, the contrast between new musicology and new empiricism could not be bolder, a contrast reminiscent of the methodological differences between the humanities and the sciences. However, in the last decade these two movements seem to have merged into a revitalized systematic musicology that is based on empirical observation and rigorous method, but at the same time is also aware of, and accounts for, the social and cultural context in which music functions (cf. Clarke \& Cook, 2004).

The question remains in how far musicology as a whole has been influenced by this new empiricism. One of the challenges of empirical musicology (and thus this journal) is to discuss how systematic and empirical methods can contribute to a further and more precise understanding of musical phenomena, as well as showing how this understanding could have an effect on musicological discourse.

\section{The Role of Formalization: Computational Musicology}

A second development in music scholarship is the growing role of formalization and the notions of testability and falsification (Popper, 1934/1959). A consistent trend in formalization, most notably in music theory, has been evident since the 1960s. Early examples are, for instance, the works by Milton Babbitt, Allen Forte, and David Lewin, but this line of research is still continuing (e.g., Lerdahl, 2001; Assayag et al., 2002). Theories in computational form (e.g., Longuet-Higgins, 1987; Temperley, 2001; Rowe, 2003) are a logical consequence of such formalization. These theories aim for a clear and determined scope, can be checked for consistency, and might be applied to and evaluated on different branches of music.

Interestingly, this has led to a greater visibility of musicology, especially outside the humanities. The fact that a theory is presented in a formal and replicable way allows for an easier formulation of hypotheses, the making of precise predictions, and, consequently, the testing and evaluation of these. As such, it makes this type of theory compelling to both computer scientists and experimental psychologists. This development could serve as an important example of how a changing methodology considered within the humanities to be of minor relevance, has a major impact outside the humanities, in that a methodology shared with the sciences served as a vehicle - a format for the transmission of ideas — that turned out to be very influential. A well-known example is Lerdahl \& Jackendoff (1983) - a highly formalized theory that, consequently, has been tested and elaborated upon in a variety of disciplines, ranging from music theory and systematic musicology to music technology and music psychology. [3]

However, it has to be noted that there are also examples that were less successful. For instance, theories on music that were developed in the sciences, such as Longuet-Higgins' work in the 1970s (Longuet-Higgins, 1987). This research did not reach the music community in the way one would have expected, even though it is presented in a compelling and formalized form. Thus, the transmission of ideas in formalized form could well be primarily unidirectional.

Whether this is a general characteristic of computational musicology is still unclear. One of the topics this new journal could address is how the methodologies adapted from experimental psychology and computer science could facilitate true interdisciplinary research in music, in the sense that knowledge is communicated in a bi-directional way between the humanities and the sciences.

\section{The Role of Computational Modeling: Cognitive Musicology}

These two developments - empirical and computational musicology — and the methods they use (i.e. empirical observation and formalization) could also be interpreted as part of a general trend in the sciences, namely the "cognitive revolution" and the central role therein of computational modeling as a methodology (Pylyshyn, 1984; Fodor, 2000). In recent decades, computational modeling has become a well-established research method in many fields, including systematic and cognitive musicology (e.g., 
Leman, 1995; Desain, Honing, Thienen \& Windsor, 1998), in what has to be acknowledged as a fruitful collaboration between the humanities and the sciences.

In an attempt to characterize the current state of affairs, one can distinguish between several approaches to computational modeling. One, for example, aims at modeling musical knowledge. These are models originating from music theory in which a thorough formalization contributes to an understanding of the theory itself, its predictions, and its scope (e.g., Lerdahl \& Jackendoff, 1983; Narmour, 1992). Another approach aims at constructing theories of music cognition. Here, the objective is to understand music perception and music performance by formalizing the mental processes involved in listening to and performing music (Clarke, 1999; Gabrielsson, 1999). The two approaches have different aims and can be seen as being complementary.

Cognitive musicology (or music cognition) is a rapidly growing field of research. In the last ten years, a number of universities in Europe and North America have established new interdisciplinary research groups with music cognition as their central research topic. Still, the promise of computational modeling as a method, i.e. being instrumental in the understanding of the structure of musical knowledge and the processes involved in music cognition (Desain, Honing, Thienen \& Windsor, 1998), has not been fulfilled as yet. While the method has had quite some impact on the way theories of music have been formulated (Longuet-Higgins, 1987; Large \& Jones, 1999; Rowe, 2003), the evaluation and possibly falsification of computational theories of music turns out to be quite a challenge (Honing, in press).

\section{The Impact of Music Scholarship on the Cognitive Sciences: Music Cognition}

In the 1970s, music was studied in the sciences mainly for its acoustical and perceptual properties, in what were then relatively novel disciplines such as psychophysics and music psychology. Music scholars criticized much of this research for focusing too much on low-level issues of sensation and perception, often using impoverished stimuli (e.g., small rhythmic fragments) or music restricted to the Western classical repertoire, as well as a general unawareness of the role of music in its wider social and cultural context (Huron, 1999a). However, the cognitive revolution made scientists more aware of the role and importance of these aspects. While twenty years ago, music was hardly mentioned in any handbook of psychology (or appeared only in a subsection on pitch or rhythm perception), it is now recognized, along with vision and language, as an important and informative domain in which to study a variety of aspects of cognition, including expectation, emotion, perception, and memory (Juslin \& Sloboda, 2001; Levitin, 2002).

\section{CONCLUSION}

The three lines of research sketched above (empirical, computational and cognitive musicology) signify a growing role of observation, formalization and experimental method in music research. There is a clear trend in studying music in a scientific way with a focus on music as a process in which the performer, the listener, and music as an observable entity play a central role. Furthermore, current music research does not just borrow from the (cognitive) sciences, it is also contributes to it in significant ways. Music, like language, is more and more considered an important domain to study cognition and culture; disciplines like evolutionary psychology, neuro-cognition, and even cognitive archeology (Mithen, 2005) recognize the importance of studying music in all its facets. The opportunities of musicologists and music theorists to contribute to this research seem to be greater than ever.

\section{NOTES}

[1] But note that, while systematic musicology may have seemed to be an extension to musicology in the late 19th century (according to Adler), one could argue that the musical questions that occupied scholars before that time corresponded almost entirely to the category systematic musicology. Hence, the paradigm shift has to be interpreted against $19^{\text {th }}$ and $20^{\text {th }}$ century musicology. 
[2] New Musicology: a branch of music scholarship that is guided by "a recognition of the limits of human understanding, an awareness of the social milieu in which scholarship is pursued, and the realization of the political area in which the fruits of scholarship are used and abused" (Huron, 1999b). In addition, subjectivity and gender are important notions in new musicology (McClary, 1991).

[3] This theory has also been a source of criticism, for example, for being not formalized enough. This prompted several refinements as well as alternatives. However, it still supports the point made that formalization invites evaluation and facilitates interdisciplinary research.

\section{ACKNOWLEDGMENTS}

This research has been made possible by the Netherlands Organization for Scientific Research (NWO). Part of this text was published in Tijdschrift voor Muziektheorie (Honing, 2004).

\section{REFERENCES}

Adler, G. (1885). Umfang, Methode und Ziel der Musikwissenschaft. Vierteljahresschrift für Musikwissenschaft 1, 5-20.

Assayag, G., Feichtinger, H.G., \& Rodrigues, J.F. (2002). Mathematics and Music. Berlin: Springer Verlag.

Clarke, E.F., \& Cook, N. (Eds.) (2004). Empirical musicology: Aims, methods and prospects. Oxford: Oxford University Press.

Clarke, E.F. (1999). Rhythm and timing in music. In D. Deutsch (Ed.), Psychology of Music, $2^{\text {nd }}$ Edition (pp. 473-500). New York: Academic Press.

Desain, P., Honing, H., Thienen, H. van, and Windsor, W. L. (1998). Computational Modeling of Music Cognition: Problem or Solution? Music Perception, 16, 151-166.

Duckles, V., \& Pasler, J. (2001). Historical and Systematic Musicology. In S. Sadie and J. Tyrrell (Eds.) The New Grove Dictionary of Music and Musicians (pp. 490-491). London: Macmillan.

Fodor, J. (2000). The Mind Doesn't Work that Way. The Scope and Limits of Computational Psychology. Cambridge, Mass.: MIT Press.

Gabrielsson, A. (1999). The performance of music. In D. Deutsch (Ed.), Psychology of Music, $2^{\text {nd }}$ Edition (pp. 501-602) New York: Academic Press.

Honing, H. (2004). The comeback of systematic musicology: New empiricism and the cognitive revolution. Tijdschrift voor Muziektheorie [Dutch Journal of Music Theory], 9(3), 241-244.

Honing, H. (In press). Computational modeling of music cognition: A case study on model selection.. In press, Music Perception. [ http://dare.uva.nl/en/record/146627 ]

Huron, D. (1999a). Foundations of Cognitive Musicology. Berkeley, University of California. [http://www.music-cog.ohio-state.edu/Music220/Bloch.lectures/]

Huron, D. (1999b). The New Empiricism: Systematic Musicology in a Postmodern Age. Berkeley, University of California. [http://www.music-cog.ohio-state.edu/Music220/Bloch.lectures/] 
Juslin, P., \& Sloboda, J. (Eds.) (2001). Music and Emotion: Theory and Research. Oxford: Oxford University Press.

Kerman, J. (1985). Contemplating Music: Challenges to Musicology. Cambridge: Harvard University Press.

Kunst, J. (1950). Musicologica: a Study of the Nature of Ethno-Musicology, its Problems, Methods and Representative Personalities. Amsterdam: Indisch Instituut.

Large, E. W., \& Jones, M. R. (1999). The dynamics of attending: how we track time varying events. Psychological Review, 106 (1), 119-159.

Leman, M. (1995). Music and Schema Theory - Cognitive Foundations of Systematic Musicology. Berlin: Springer Verlag.

Lerdahl, F. (2001). Tonal Pitch Space. Oxford: Oxford University Press.

Lerdahl, F. \& Jackendoff, R. (1983). A Generative Theory of Tonal Music. Cambridge, MA: MIT Press.

Levitin, D. (Ed.) (2002). Foundations of Cognitive Psychology: Core Readings. Cambridge, MA: MIT Press.

Longuet-Higgins, H.C. (1987). Mental Processes. Studies in Cognitive Science. Cambridge, MA: MIT Press.

McClary, S. (1991). Feminine Endings: Music, Gender, and Sexuality. Minneapolis: University of Minnesota Press.

Mithen, S. (2005). The Singing Neanderthal: The Origin of Language, Music, Body and Mind. London: Wiedenfeld \& Nicolson.

Narmour, E. (1992). The Analysis and Cognition of Basic Melodic Structures: The Implication-Realization Model. Chicago: Chicago University Press.

Nattiez, J.J. (1987). Musicologie générale et sémiologie. Paris: C. Bourgois; Eng. trans., 1990, as Music and Discourse. Princeton, NJ: Princeton University Press.

Natoli, J. (1997). A Primer on Postmodernity. Oxford: Blackwell Publishers.

Popper, K. (1959). The Logic of Scientific Discovery. London: Routledge. Originally published as Logik der Forschung, Berlin: Springer, 1934.

Pylyshyn, Z. W. (1984). Computation and Cognition: Toward a Foundation for Cognitive Science. Cambridge, Mass.: MIT Press.

Rink, J. (Ed.) (1995). The Practice of Performance: Studies in Musical Interpretation. Cambridge: Cambridge University Press

Rowe, R. (2003). Machine Musicianship. Cambridge, Mass.: MIT Press.

Seeger, A. (1991). Styles of Music Ethnography. In B. Nettl and P.V. Bohlman (Eds.) Comparative Musicology and Anthropology of Music (pp. 342-55). Chicago: The University of Chicago Press.

Temperley, D. (2001). The Cognition of Basic Musical Structures. Cambridge, MA: MIT Press. 